\section{Identification of skeletal muscle mutations in tail snips from neonatal mice using immunohistochemistry}

\author{
Richard M. Lovering, Andrea O'Neill, Joseph A. Roche, and Robert J. Bloch \\ University of Maryland School of Medicine, Baltimore, MD, USA
}

BioTechniques 42:702-704 (June 2007)

doi $10.2144 / 000112488$

Naturally occurring or laboratorygenerated genetic modifications of striated muscle in mice have been linked to cardiomyopathies or muscular dystrophies (1-4). Such mutations are generally recognized by recombinant DNA techniques, especially PCR, but uncertainties about the genetic locus of particular mutations and variations in DNA sequences among different strains of mice may limit the usefulness of this approach. We investigated the possibility of using tail snips, typically obtained for PCR analysis, for immunofluorescence assays of muscle proteins. We report here that skeletal muscle fibers present in the distal 1-cm-end of the tail of the neonatal mouse can be assayed using immunohistochemistry to identify desmin null (5), dysferlin null (6), and dystrophin null muscles. Identification of these muscles by immunofluorescent assays allows phenotypic conformation of genetic screening of mutant mice, facilitating evaluation of muscle from only those animals expressing the genotype of interest.

Standard tail snips, approximately $1 \mathrm{~cm}$ in length, were collected from young mice ( $<4$ weeks of age) and used for PCR or immunofluorescence analysis or both. The tails were swabbed with alcohol, and sterile surgical scissors were used to obtain tissue. For immunolabeling, tissue $(\leq 5 \mathrm{~mm})$ was mounted with optimal cutting temperature (OCT) medium and snap-frozen in pentane-cooled liquid nitrogen. Serial cross-sections, $10 \mu \mathrm{m}$ in thickness, were prepared with a cryostat, collected on glass slides (Superfrost ${ }^{\circledR}$ Plus; VWR, West Chester, PA, USA), incubated with phosphatebuffered saline (PBS) containing 3\% bovine serum albumin (BSA) for $1 \mathrm{~h}$, and labeled with primary antibodies diluted in the same solution to muscle myosin (mouse 1:500; Sigma-Aldrich, St. Louis, MO, USA) and desmin (rabbit 1:100; Neomarkers, Fremont,

\section{B}
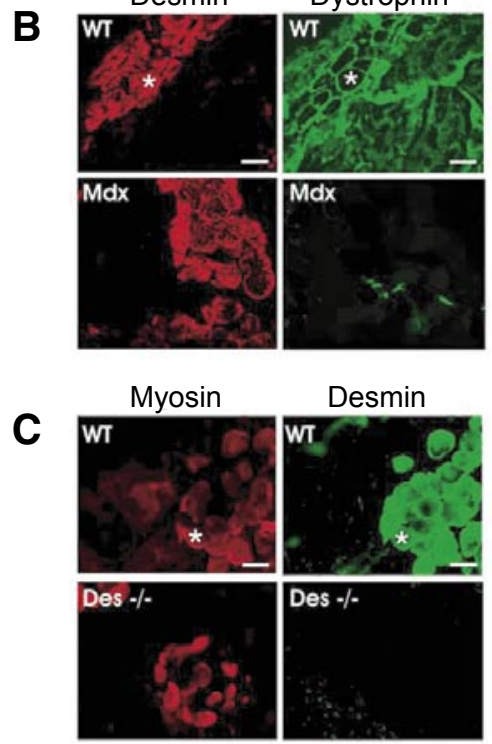

D

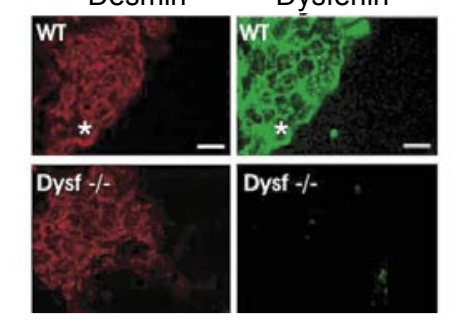

CA, USA), a muscle-specific intermediate filament protein. Other serial sections were labeled with antibodies to desmin and dystrophin (mouse 1:5; Novocastra, Newcastle upon Tyne, UK) or desmin and dysferlin (mouse 1:100; Novocastra). Sections were washed three times for $10 \mathrm{~min}$ with PBS, then incubated in speciesspecific secondary antibodies coupled to Alexa dyes (Invitrogen, Carlsbad, CA, USA). Samples were mounted in VECTASHIELD ${ }^{\circledR}$ (Vector Laboratories, Burlingame, CA, USA) and covered with glass coverslips (VWR), before examination under epifluorescent optics (Zeiss Axioskop ${ }^{\circledR}$ 50, Carl Zeiss, Poughkeepsie, NY, USA). All labeling of wild-type tail muscle was specific, as judged by the use of appropriate preimmune serum.

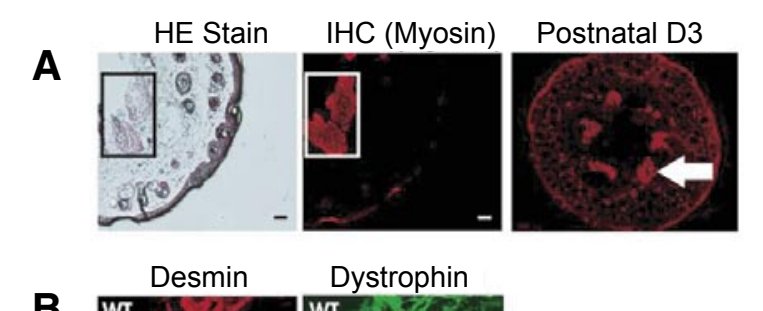

Figure 1. Muscle fibers in the distal tail. All images are from the distal tail after standard a tail snip procedure of mice $<4$ weeks old. Part of the tail snip was cut and mounted for cryosectioning $(10 \mu \mathrm{m})$. (A) Serial sections were stained with hematoxylin and eosin (HE; left) and with antibodies against muscle myosin and fluorescent secondary antibodies (red; right panels). Muscle fibers (outlined by rectangle) were typically present in clusters close to the center of the tail. The central bone (vertebral segment) was cut away during cryosectioning. The arrow indicates myofibers labeled for desmin, a muscle-specific marker, in the distal tail from a 3-day-old mouse. IHC, immunohistochemistry. (B) Muscle section (four times original magnification) labeled with antibodies against desmin (red), and dystrophin (green), a membrane-associated protein present in wild-type mouse muscle, but missing in muscle from the $\mathrm{mdx}$ mouse, 2 weeks of age. Asterisks indicate the same fiber in two different sections. (C) Labeling for muscle myosin (red) and desmin (green). Desmin is confirmed missing in the distal tail of the desmin -/- mouse at 2 weeks of age. (D) Labeling for muscle myosin (red) and dysferlin (green) of wild-type and dysferlin -/- mice. Scale bar, $50 \mu \mathrm{m}$. WT, wild-type. 


\section{Benchmarks}

Skeletal muscle fibers were apparent in tail snips by standard hematoxylin and eosin (HE) stain (Figure 1A, left). Positive labeling with antibodies to muscle myosin and desmin confirmed that these were muscle fibers (Figure 1, A-D). Confirmation of the usefulness of labeling tail snips as a supplement to genotyping was obtained by labeling samples from dystrophin null $(\mathrm{mdx})$ (Figure 1B), desmin null (Figure 1C), and dysferlin null (Figure 1D) mice at 2 weeks of age.

When genotyping works well, immunolabeling of skeletal muscle fibers in the mouse tail may be unnecessary; immunolabeling can be timeconsuming and, like PCR, is subject to possible false-positive or false-negative findings. However, when problems arise with primers or PCR, or simply when very extensive in vivo experiments are planned, immunofluorescence assays of tail snips can be used to confirm the absence of a specific protein in skeletal muscle without additional harm to the animal. Tail snips are already widely used to obtain tissue for genotying (7). Labeling some of this tissue by immunofluorescence will likely not entail significant modification of protocols already approved for tail snips of mice studied before weaning. DNA isolation kits recommend using from 0.7 to $1.2 \mathrm{~cm}$ from the mouse tail. Thus, typical tail snips contain more than enough material for both immunofluorescence labeling and PCR, and we have used several samples for both assays. This method, which works with mice as young as 1 day old, as well as with older animals, has allowed us to confirm the lack of desmin in skeletal muscle prior to proceeding with experiments to study contractile activity, sample creatine kinase in the serum over time, and perform other in vivo assays.

\section{COMPETING INTERESTS STATEMENT}

The authors declare no competing interests.

\section{REFERENCES}

1. Boriek, A.M., Y. Capetanaki, W. Hwang, T. Officer, M. Badshah, J. Rodarte, and J.G. Tidball. 2001. Desmin integrates the three-dimensional mechanical properties of muscles. Am. J. Physiol. Cell Physiol. 280:C46-C52.

2. Lovering, R.M., N.C. Porter, and R.J. Bloch. 2005. The muscular dystrophies: from genes to therapies. Phys. Ther. 85:1372-1388.

3.O'Neill, A., M.W. Williams, W.G. Resneck, D.J. Milner, Y. Capetanaki, and R.J. Bloch. 2002. Sarcolemmal organization in skeletal muscle lacking desmin: evidence for cytokeratins associated with the membrane skeleton at costameres. Mol. Biol. Cell 13:2347-2359.

4. Straub, V., J.A. Rafael, J.S. Chamberlain, and K.P. Campbell. 1997. Animal models for muscular dystrophy show different patterns of sarcolemmal disruption. J. Cell Biol. 139:375-385

5. Milner, D.J., G. Weitzer, D. Tran, A. Bradley, and Y. Capetanaki. 1996. Disruption of muscle architecture and myocardial degeneration in mice lacking desmin. J. Cell Biol. 134:1255-1270.

6. Bansal, D., K. Miyake, S.S. Vogel, S. Groh, C.C. Chen, R. Williamson, P.L. McNeil, and K.P. Campbell. 2003. Defective membrane repair in dysferlin-deficient muscular dystrophy. Nature 423:168-172.

7. Wang, Z. and D.R. Storm. 2006. Extraction of DNA from mouse tails. BioTechniques 41:410-412.

Received 14 March 2007; accepted 18 April 2007.

Address correspondence to Richard $M$. Lovering, University of Maryland School of Medicine, Department of Physiology, 685 W. Baltimore Streeet, HSF-1, Rm 580, Baltimore, MD 21201, USA. e-mail: rlovering@som.umaryland.edu

To purchase reprints of this article, contact: Reprints@BioTechniques.com 